\title{
Ciber-Cultura Feminina: interação social em um weblog
}

\author{
Adriana Braga ${ }^{1}$ \\ adrianabraga1@yahoo.com.br
}

\begin{abstract}
Resumo: Proponho neste artigo desenvolver uma reflexão sobre algumas práticas comunicacionais estabelecidas na ambiência proporcionada pela Internet - especificamente, as interações registradas em texto entre um grupo de mulheres jovens, que tematizam a maternidade em suas trocas no interior do Livro de Visitas de um weblog. A partir de uma perspectiva simmeliana, relaciono a mulher e a cultura e a dimensão de sociabilidade na cibercultura. Em particular, me interessa analisar a dinâmica interacional da entrada em cena de novas participantes, a negociação de sentidos em situações de conflito e uma teorização informal da feminilidade ali observável.
\end{abstract}

Palavras-chave: Comunicação Mediada por Computador (CMC); sociabilidade; Weblog.

\begin{abstract}
In this paper, I discuss some communicative practices ocurrant on the Internet, specifically, the written social interactions of a group of young women regarding motherhood in the context of a weblog's guestbook. Since a Simmelian perspective, I relate women and culture and sociability in cyberculture. In particular, I wish to analyse the interactional dynamics concerning newcomers, the negotiation of meanings during conflicts and an informal theorization of femininity found there.
\end{abstract}

Key-words: Computer-mediated communication (CMC); sociability; weblog.

Résumé: En cet article, j'analyse quelques pratiques communicationelles qui se déroulent dans l'Internet, plus specifiquement, les interactions écrites d'un groupe de jeune femmes à propos de la maternité dans le milieu de le Livre d'or d'um weblog. Depuis d'une perspective Simmelienne, je rapporte les femmes et la culture et'la sociabilité dans le cyberculture. En particuler, janalyse la dynamique interactionel dans les venues des novices, la negociation des signifiés pendent des conflites et une théorization informal de la feminité que se trouve lá.

Mots clés: Communication Médiée par Ordinateur (CMO); Sociabilité; weblog

1 Doutora em Ciências da Comunicação 
Resumen: En este artículo, analiso algunas prácticas comunicacionales que ocurren em Internet, más especificamiente las interacciones escritas de um grupo de jóvenes mujeres cerca de la maternidad en el ambiente del Libro de Oro de um weblog. Desde una perspectiva simmeliana, relaciono la mujer y la cultura, asi como la sociabilidad en la cybercultura. En particular, analiso la dinámica interaccional relativa a la enrada de las novatas, la negociación de sentidos en situaciones de conflito y la teorización informal de la feminidad que ocurre allí.

Palabras-llave: Comunicación mediada por Computadora (CMC); sociabilidad; weblog..

\section{Introdução}

Neste artigo, desenvolvo uma reflexão sobre práticas comunicacionais estabelecidas na ambiência proporcionada pela Internet - nomeadamente, as interações ocorrentes no Livro de Visitas (LV) de um weblog, inscrevendo-se em uma abordagem da ecologia das mídias. Logan (2002) localiza o início da perspectiva ecológica das mídias às acepções mcluhanianas, ${ }^{2}$ pioneiras na preocupação com o papel dinâmico das mídias e da tecnologia nos ambientes econômico, político, social e cultural. Nesse sentido, a perspectiva ecológica das mídias agrega como aspectos da comunicação os estudos das mídias, da tecnologia e da linguagem, e a interação entre esses três domínios, entendidos como um ecossistema (Logan, 2002).

Os weblogs são aqui entendidos como um ambiente específico possibilitado pelo suporte técnico e seus usos, que originam modalidades interacionais peculiares. Em particular, me interessa o uso que as participantes do grupo observado fazem do aparato técnico fornecido pelo computador pessoal ligado à WWW, os modos de apropriação por esse grupo do novo ambiente social disponibilizado pela Internet, o modo como interagem com as tecnologias de comunicação recentes. Nesse sentido, apresento três modalidades de interação e comportamento nesse espaço social, espaço público contemporâneo.

\footnotetext{
${ }^{2}$ A recuperação das proposições e hipóteses de McLuhan, que tiveram grande vigor na década de 1960, apresentando um ponto de vista então revolucionário sobre aquele novo objeto de pesquisa, a mídia, apresenta-se na literatura do século XXI ora de forma crítica e até irônica pelo caráter religioso que esse legado assume, ora analiticamente, em um esforço de revigoramento de seus conceitos.
} 
Tomo como ponto de observação o contexto interacional estabelecido no ambiente do LV de um weblog específico, o Mothern (www.mothern.blogspot.com). O título deste weblog resulta da contração entre as palavras mother + modern, deixando clara a relação entre os domínios da maternidade - tema por excelência da cultura feminina - e o contexto da modernidade. Assim, este locus de investigação ${ }^{3}$ apresenta um conjunto concentrado de variáveis diretamente pertinentes aos objetivos desta reflexão: feminilidade, cibercultura e comunicação.

\section{Interação Social e Apresentação do Self na Cibercultura}

Desde a criação de interfaces simplificadas para veiculação de conteúdos online, os ambientes de Internet passaram a ser largamente utilizados por usuárias/os não especializados/as como meio de expressão individual e coletiva, operando como um espaço social para apresentações do self, onde são veiculadas representações de identidade e de individualidade, em uma dinâmica análoga ao que Goffman (1998) denomina "gerenciamento da impressão" (impression management). Essa tecnologia permitiu então que algumas das mulheres que já lidavam com computadores em suas atividades profissionais e/ou cotidianas, utilizassem essa tecnologia para criar weblogs temáticos, voltados exclusivamente para assuntos "femininos." Nesse contexto, são travadas negociações de sentidos em torno da constituição dos papéis de gênero. Tais negociações se dão de forma bastante peculiar estabelecendo a interação ocorrente no Livro de Visitas. A interatividade e o recurso de utilização da hipertextualidade característica dos weblogs proporciona a formação de uma listagem de indicação de links constituída a partir dos interesses temáticos do grupo, o que gera uma rede de interações comunicativas e circulação de saberes específicos por essa via. Desta forma, ampliou-se a oferta de sentidos acerca das representações do "feminino" no campo das mídias, trazendo novas expressões ao já intrincado e complexo campo simbólico das representações midiáticas.

Buscando lidar com um objeto de natureza tecnológica, é preciso evitar tanto a tentação do determinismo quanto da negação que este tipo de objeto suscita. Assim,

\footnotetext{
$3 \mathrm{O}$ conjunto dos dados para o projeto de investigação do qual esse artigo deriva inclui, além do conteúdo do weblog citado, material proveniente de entrevistas com informantes, da participação em encontros presenciais, da comunidade Mothern no Orkut e de outros weblogs relacionados.
} 
reconheço na abordagem de Ong (1998) um meio termo sensato, que, a partir de uma perspectiva histórica, realoca a oralidade no lugar de originadora da cultura escrita. A escrita, considerada como tecnologização da palavra, por estar tão incorporada ao próprio pensamento humano, tem sua forma e organização tomadas como óbvias, dadas. ${ }^{4}$ As semelhanças e diferenças entre oralidade e escrita, entretanto, apontam aspectos interessantes de sub-culturas de sociedades de cultura escrita de alto grau como a nossa, onde fragmentos de oralidade podem ser identificados, revelando aspectos de grande interesse de estudo. Na passagem da fala para a escrita, opera-se um desvio do universo sonoro para o espaço visual (Ong, 1998, p. 135). Nesse sentido, observa-se no LV um modo freqüente e curioso de expressão, registros por escrito com ritmo e expressividade característicos de formas basicamente orais.

Este uso subversivo da língua culta - aquela dos documentos formais reitera o distanciamento eletivo do mundo do trabalho, e a conseqüente adesão ao descompromisso próprio da sociabilidade. Uma distinção importante é ressaltada por Ong com relação à escrita e à oralidade, e parece se aplicar aos dados de campo:

A escrita e a leitura diferem da oralidade, em termos de ausência: o leitor está normalmente ausente quando o escritor escreve, e o escritor está normalmente ausente quando o leitor lê, ao passo que, na comunicação oral, falante e ouvinte estão presentes, um diante do outro (Ong, 1998, p. 191).

Para Ong, uma das diferenças operadas pelo surgimento da escrita com relação à cultura oral foi a introdução de um tipo de reflexão analítica até então inexistente. Livre da obrigatoriedade da presença física do outro e da concomitante necessidade do improviso demandada pela cultura oral, a cultura escrita permite tempo para reflexão, para escolher as melhores palavras. Com isso, ganha-se em precisão verbal, mas perde-se um pouco em espontaneidade. Em nossa época de oralidade secundária - oralidade pós-tecnologia da escrita -, a promoção da espontaneidade se dá através da reflexão analítica operada pela escrita: decide-se que é conveniente ser espontâneo (Ong, 1998, p. 155). Sendo assim, os acontecimentos são cuidadosamente planejados visando garantir a espontaneidade.

\footnotetext{
4 Entretanto, a experiência proporcionada pelos meios de comunicação tem influenciado a auto-identidade e a organização das relações sociais desde a primeira experiência da escrita (Giddens, 2002, p. 12).
} 
Mais de 20 anos após a publicação do livro, escrito em 1982 - antes ainda das possibilidades comunicacionais da tecnologia da Internet -, Ong (2003) dedica seu último artigo publicado, antes de sua morte em 2003, a uma reflexão sobre a alteração da consciência a ser operada nos seres humanos a partir da entrada em cena do horizonte comunicacional aberto pela atividade on-line. De olhos no futuro, o autor se pergunta "onde estamos agora" (Ong, 2003, p. 43), na medida em que, a partir da Internet e da atividade on-line, tudo no mundo da vida humana está conectado conscientemente com tudo o mais: o que é externo e interno à mente humana. A considerar a crescente expansão do processamento eletrônico, o autor demonstra seu assombro diante da concepção de um tempo em que o mundo interior da consciência e o mundo exterior passam a ser (virtualmente) um só (Ong, 2003, p. 44). Sob a suspeita de que esse é o mundo que se estabelece para o futuro inteiro da existência, Ong parece atentar para as conseqüências desse estado de coisas na própria consciência humana, como quando da entrada da cultura escrita na cultura oral, da cultura impressa na cultura escrita e agora, da cibercultura na cultura impressa/audiovisual.

Assim, a introdução de uma nova tecnologia em dada cultura implica uma reorganização desta nos mais diversos níveis, promovendo novo repertório de palavras, novos protocolos de interação, nova visão de mundo. A partir disso, não se tem a cultura mais a nova tecnologia, mas uma outra cultura. Nos termos de Neil Postman, "a mudança tecnológica não é nem aditiva nem subtrativa. É ecológica. Refiro-me a 'ecológica' no mesmo sentido em que a palavra é usada pelos cientistas do meio ambiente. Uma mudança significativa gera uma mudança total” (Postman, 1994, p. 27).

Como um exemplo, a introdução da Internet permitiu, entre outras coisas, uma certa relativização do monopólio de produção de conteúdos midiáticos, vigente desde o surgimento dos meios eletrônicos. Evidentemente, em termos de impacto de veiculação nenhum conteúdo de Internet pode ainda rivalizar com um programa de televisão. Porém, o fato de não requerer do/a produtor/a um investimento expressivo, e de não necessitar enfrentar as chamadas 'barreiras à entrada' (Brittos,

\footnotetext{
${ }^{5}$ Como exemplos, pode-se pensar nas alterações promovidas na cultura com a introdução da escrita, da imprensa e do telefone.
} 
2004) presentes no estruturado mercado de televisão, os weblogs têm sido empregados pelos mais diversos perfis de produtores/as, colocando no campo discursivo midiático um número expressivo de novos sujeitos enunciadores. Essa conseqüência, provavelmente não prevista pelos/as criadores/as desta tecnologia, tem permitido a emergência de fenômenos como o analisado neste artigo.

\section{Simmel, Goffman e a sociabilidade digital}

No que se segue, recupero um pouco da trajetória do raciocínio de Simmel na sua teoria da sociedade desenvolvida ainda no final do século XIX para pensar posteriormente algumas modalidades de interação que ocorrem nos weblogs. Duas proposições são trabalhadas por Simmel (1983, p. 165) para descrever a constituição da "sociologia pura:" a de que em qualquer sociedade humana é possível fazer uma distinção entre forma e conteúdo; e de que a própria sociedade se refere à interação entre seus membros, interação originada a partir de impulsos ou propósitos. Os indivíduos vivem, agem, uns com ou contra os outros se influenciando mutuamente a partir de impulsos eróticos, religiosos, interesses objetivos, propósitos de auxílio, defesa, ataque, de ganho, de jogo etc. Esse autor designa como conteúdo, como matéria da sociação - entendida aqui como a forma pela qual os indivíduos se aproximam em núcleos de satisfação de seus interesses - o que está presente nos indivíduos na forma de impulso, interesse, inclinação, propósito, estado psíquico, movimento que visa mediar influências sobre os outros. A base das sociedades humanas é formada por tais interesses, sejam eles efêmeros, permanentes, conscientes ou não, sensuais, ideais ou causais.

Simmel vai chamar de sociabilidade um fenômeno desta ordem. Considerando a distinção entre forma e conteúdo, o conteúdo da sociedade seria estar com um outro motivado pelos propósitos individuais ou materiais, o qual conformaria formas estéticas específicas que, desenvolvidas, ganhariam vida própria. Tais formas, autonomizadas, independentes de seus conteúdos originais, adquirem fascínio exatamente por esta desvinculação: sociabilidade, forma autônoma, estética e lúdica da sociação. ${ }^{6}$

\footnotetext{
${ }^{6}$ Cabe destacar que a sociabilidade é uma das principais modalidades de interação no LV, mas não a única. Eventualmente, ocorrem conflitos abertos, com conseqüências para a
} 
Sendo assim, a sociabilidade evita atritos com a realidade, de modo que os motivos da sociação, implicados na vida prática, não têm importância neste contexto interacional. Ponto semelhante é desenvolvido por Goffman, para quem a maior parte da interação social cotidiana é possibilitada pelo engajamento comum e voluntário dos/as participantes no que ele chama de "consenso operacional" (Goffman, 1998), uma espécie de concordância superficial, onde cada participante abstrai suas posições pessoais em prol de uma definição da situação compartilhada por todos/as:

A conservação desta concordância superficial é facilitada pelo fato de cada participante ocultar seus próprios desejos por trás de afirmações que apóiam valores aos quais todos os presentes se sentem obrigados a prestar falsa homenagem. (...) Os participantes, em conjunto, contribuem para uma única definição geral da situação, que implica não tanto num acordo real quanto às pretensões de qual pessoa, referentes a quais questões, serão temporariamente acatadas, haverá também um acordo real quanto à conveniência de se evitar um conflito aberto de definições da situação. Referir-me-ei a este nível de acordo como um "consenso operacional" (Goffman, 1998, pp. 18-19).

Mesmo com toda a mediação tecnológica, a interação no LV parece não prescindir do encontro face a face. Por vezes, as freqüentadoras efetivamente promovem encontros presenciais, mais aos moldes da sociabilidade descrita por Simmel. Os encontros são concebidos, planejados e comentados no ambiente do LV, e documentados em fotologs das participantes, permitindo pensar em uma dimensão complementar das diferentes mídias coexistentes no cotidiano das freqüentadoras. Nesse caso, as relações mediadas pelas tecnologias participam do contexto da interação, e a propósito dela: $w e b l o g$ + bar + e-mail + MSN + celular + fotografia digital + fotolog + lista de discussão restrita + Orkut. Esta espécie de interação, assemelhada à de um clube, associação de interesses compartilhados, utiliza as mídias disponíveis de modo complementar, a serviço da sociação.

Se por um lado, a teorização de Goffman sobre a ordem da interação face a face parece se aplicar muito bem ao objeto sob investigação, por outro, os dados apontam também diferenças importantes. Goffman considera que há duas espécies

configuração do grupo de participantes e suas redes de lealdade, tema a ser detalhado no capítulo de análise. Para uma discussão aprofundada das peculiaridades da sociologia formal de Simmel, ver Smith (2004). 
de expressividade do indivíduo, atividades radicalmente diferentes e igualmente significativas: a expressão transmitida, ligada à linguagem verbal e à intencionalidade, e a expressão emitida, que inclui os gestos, olhares, suores, sorrisos ou expressões faciais, permitindo inferências nem sempre controladas pelo indivíduo. No caso do weblog, há menos elementos de emissão de expressão, somente aqueles veiculáveis por forma verbal - erros de português, por exemplo - havendo uma preponderância da informação deliberadamente transmitida. Isso traz conseqüências ao tipo de interação comunicacional que se estabelece. Relativamente livres da expressividade via emissão, os sujeitos encontram menos obstáculos - ou obstáculos de outra ordem - em tentar manejar a impressão causada através de pseudônimos, nicknames, tentativas de controle com relação à informação fornecida.

No contexto específico do weblog, em que sejam guardadas as diferenças do tipo de interação face a face analisada por Goffman, ${ }^{7}$ a dinâmica interacional entre as participantes aponta para a manutenção do consenso operacional deste ambiente de interação. Quando uma das participantes traz ao LV um assunto pessoalmente importante naquele momento, as demais freqüentadoras imediatamente acolhem aquele conteúdo emitindo opiniões sensatas, de apoio, que se reiteram, estabelecendo esse consenso. Tal acordo tácito parece pretender mais acatar a pessoa que expôs seu problema do que obter uma concordância real sobre a situação em si.

A função reguladora da interação vai ser exercida através da amabilidade e cordialidade, que vai traçar os limites quando ocorrerem excessos. Não participam aqui diretamente quaisquer atributos mais objetivos que os/as participantes possuam, como riqueza, posição social, fama, cultura, bem como o caráter, a disposição pessoal, devem ser colocados em segundo plano como elementos desse ambiente de interação, ${ }^{8}$ exceto cumprindo um papel de meros matizes.

No contexto do LV, esse limiar é eventualmente transposto quando alguma participante comete um excesso, fazendo uma crítica explícita a algum conteúdo

\footnotetext{
7 Em seus textos, Goffman deixa sempre claro o limite da ordem da interação: a presença física imediata entre dois/duas ou mais participantes. Entretanto, no tempo em que Goffman escreveu, não existia Internet. Acredito que a teorização desse autor possa ser extrapolada de modo a incluir o tipo peculiar de interação social ocorrente nos weblogs, evidentemente tendo em vista as diferenças.

${ }^{8}$ Embora o discurso inevitavelmente apresente marcas que apontam para todos esses aspectos.
} 
tratado, por exemplo. Entretanto, é interessante notar nesses casos que a reação provocada no grupo depende de quem faz a crítica. Assim, a categoria "participante" não é homogênea. Existe uma espécie de hierarquização que se manifesta, por exemplo, no retorno dado a uma crítica no contexto do LV, que pode ir do ostracismo, ironia ou agressão até uma justificativa respeitosa acerca do ponto criticado. No primeiro caso, quando a crítica parte de uma visitante anônima ou desconhecida, e no segundo, quando parte de alguma visitante prestigiosa da blogosfera. Ou seja, estabelece-se naquele ambiente uma espécie de julgamento das questões em conflito, em que a posição vencedora é a que capitaliza mais manifestações de apoio e de maior peso simbólico, definindo, nos termos do grupo, padrões de 'certo' e 'errado.' Assim, granjear o apoio expresso das co-participantes garante reconhecimento e pertencimento naquele local. Nos casos de rechaço da crítica, um argumento que freqüentemente é empregado para encerrar a questão consiste em um apelo aos objetivos declarados daquele espaço como um local de escape das atribulações diárias, como um "boteco," metáfora favorita de descrição do ambiente pelo grupo.

Este tipo de ameaça, um risco para o que parece ser o propósito puramente lúdico da sociabilidade pela introdução de assuntos objetivos ficou evidente em alguns episódios observados no LV e em outros ambientes de weblog, apresentando características de interação diferenciadas daquelas apresentadas pela sociabilidade, deixando perceber o desenvolvimento de outra forma de sociação, o conflito.

A importância sociológica do conflito (kampf) é problematizada por Simmel (1983) de forma original. Enquanto admite-se que o conflito modifique ou até produza grupos de interesse, o autor se pergunta se o conflito, independente de qualquer fenômeno do qual resulte ou acompanhe, é, em si mesmo, uma forma de sociação. Apesar do conflito ser motivado por fatores de dissociação, é também um modo de se conseguir algum tipo de unidade. Assim, o conflito pode ser visto como algo positivo, na medida em que ambas as formas de relação, a divergente ou a convergente, se diferenciam fundamentalmente da indiferença entre indivíduos ou grupos, que seria nesse sentido puramente negativa. É da divergência de ânimos e direções de pensamentos que fluem a estrutura orgânica e a vitalidade do grupo. Ao contrário do que pode parecer, unidade e discordância são tipos de interação que não 
se anulam, mas se somam; e mesmo que a discordância possa ser destrutiva em relações particulares, não tem necessariamente o mesmo efeito no relacionamento total do grupo, podendo até ter um papel inteiramente positivo nesse âmbito mais abrangente. As hostilidades preservam limites no interior do grupo e muitas vezes garantem suas condições de sobrevivência. O poder de rebeldia contra tiranias, arbitrariedades, mau-humor contribui para a manutenção da relação com participantes cujo temperamento não poderia ser suportado de outra forma.

A seguir, discuto três categorias de interação social ocorrentes em ambientes digitais, obtidas a partir da análise do referido weblog.

\section{Entrada em Cena: alguns protocolos digitais}

A comunicação através da Internet tem características específicas e cumpre rituais próprios, diferenciados de outros contextos relacionais. A chegada de um/a novo/a participante no ambiente interacional do LV é motivada pela aparição das blogueiras em um produto de mídia impressa ou eletrônica, por indicação de amigas que já freqüentam o LV. No início das atividades da homepage, as blogueiras divulgaram sua atividade utilizando suas listas de e-mail pessoais. Em resposta, escreveram para o LV diversos amigos/as e familiares, com mensagens de congratulações e estímulo pela iniciativa. Nas mensagens deixadas em todas estas situações, é possível identificar padrões interacionais, tanto na entrada no ambiente quanto no tipo de reação que essa entrada provoca.

O Mothern está em atividade há cinco anos, mantendo a ele associado o LV por quase igual período, onde participantes e freqüentadoras entram em cena a partir de um primeiro comentário em que se apresentam, e como retorno podem receber comentários de outras participantes. É interessante notar que os comentários deixados pela primeira vez no LV, na grande maioria dos casos, utilizam o elogio como senha de acesso ao ambiente interacional. A maternidade, tema principal do weblog, participa do conteúdo veiculado pela mensagem de apresentação, mas o elogio é o principal recurso utilizado para a aceitação no grupo. São amigos/as, pessoas recomendadas por amigos/as, colegas de trabalho, parentes e desconhecidos/as que encontraram o endereço através de menções ao weblog em revistas, jornais, televisão ou outros websites. A reação ao elogio é, invariavelmente, 
o acolhimento amável das blogueiras ou das outras freqüentadoras, como em vários exemplos observados, em que fica clara a seqüência elogio-réplica de acolhimento.

Muitas vezes, o elogio precede um pedido de informação. Nestes casos, o elogio opera como mediador do acesso ao ambiente, uma espécie de dádiva de cordialidade, que provoca um efeito de rápido reconhecimento. Em alguns casos, a entrada em cena se dá de outras formas. Certas mensagens têm um tom mais neutro, em que, sem um elogio prévio, é apresentada diretamente uma demanda, dica, sugestão ou comentário genérico, modalidade interacional a que tenho chamado de "não-elogio," mensagens geralmente bem recebidas.

Entretanto, às vezes, a entrada se dá de modo bastante turbulento, com críticas muitas vezes severas ao conteúdo tratado no LV. Nestes casos - pouco comuns - a reação das freqüentadoras é rápida e fulminante. Por vezes, uma mensagem crítica de um/a recém-chegado/a pode suscitar um thread ${ }^{9}$ volumoso, que levanta questões centrais acerca da organização daquele espaço. Às críticas quanto aos conteúdos, se opõe a firme posição que define o LV como espaço de absoluta liberdade de expressão à disposição das freqüentadoras, enquadrando as críticas como "patrulhamento" inaceitável.

É interessante notar que, quando um atrito aberto ocorre, a réplica das freqüentadoras busca o argumento de rechaço à crítica recebida na definição deste ambiente comunicativo e público como espaço próprio e livre. Esse padrão defensivo pode ser observado em vários outros conflitos ocorrentes no $\mathrm{LV}$, a exemplo de outros weblogs, geralmente definidos por seus blogueiros/as como local privado em que os "de casa" impõem as regras e os incomodados que se retirem.

Em um ambiente tão amplo quanto a Internet, no qual todos/as participantes podem veicular conteúdos livremente, a legitimação se dá através de alguns mecanismos identificáveis, capital específico deste campo em formação. Sendo assim, como em outro ambiente social qualquer, no espaço dos weblogs buscase legitimação a partir do reconhecimento pelos pares, o que torna a interação das participantes com tais personagens diferenciada de outros/as freqüentadores/as daquele ambiente. Ao invés do rechaço automático ou da acusação de patrulhamento,

${ }_{9}$ Conjunto de comentários a propósito de um mesmo tópico em interações on-line. 
o que se vê é um acolhimento bastante compreensivo da visitante e de seu ponto de vista.

\section{Conflito: ruptura e integração}

Os ambientes sociais proporcionados pelos weblogs têm na maioria das vezes o clima amável resultante do encontro de pessoas que compartilham interesses, pontos de vista e estilos de vida. Entretanto, por se tratar de um espaço público, que se auto-organiza, pode-se verificar a ocorrência de conflitos de vulto gerados por motivações diversas. No Mothern, os conflitos geralmente apresentam como tema questões relacionadas a comportamentos e papéis sociais femininos. Nesses episódios, pontos de vista tradicionais competem por legitimidade com posições mais tolerantes e alargadas, configurando na resultante desses processos uma espécie de identidade coletiva daquele grupo.

Conflitos emergem de diversas maneiras em ambientes de Internet. Sem pretender esgotar as possibilidades neste sentido, neste tópico ressaltarei algumas modalidades observadas no ambiente de pesquisa. A irrupção de um conflito pode dar-se pela explicitação, de uma freqüentadora, de um ponto de vista com relação a algum assunto que provoque a discordância direta de outra participante. Outras vezes, um entendimento equivocado das participantes sobre os termos de uma crítica - mesmo bem-intencionada - pode levar a um enquadramento da crítica como ofensa moral, que deflagra violentas reações. A dinâmica comunicacional estabelecida nesse espaço pode também oferecer ambigüidades com relação à mensagem veiculada e gerar mal-entendidos, que resultam em conflitos. O uso abusivo do anonimato possibilitado pela tecnologia da Internet, com a nítida intenção de desqualificação do ambiente, apesar de ter sido mais explorado no início das atividades na rede, pode ainda ser origem de situações conflitivas. Como um último aspecto desta forma interacional, destacaria uma certa disposição das freqüentadoras em participar coletivamente de contendas dessa ordem, dispondo-se mesmo a se deslocar para outro weblog amigo na intenção de defender blogueiros/as com propostas afins.

Nesse sentido, é interessante notar como, em uma situação de antagonismo contra um poder exterior, parece necessária uma centralização do grupo, que provoca 
intensificação de sua unidade e estreitamento de relações entre seus/suas integrantes. Entretanto, estas situações parecem aproximar tão estritamente os/as participantes em um impulso tão uniforme, que é necessário concordar ou se repelir completamente. Como conseqüência, em situações de conflito, os grupos tendem a ser intolerantes, criando uma unidade sem resíduos para uma ação isolada, que, uma vez vencida ou derrotada, retorna à existência independente de cada um de seus elementos (Simmel, 1983).

Um dos motivos para a irrupção de um conflito no grupo é a discordância frontal entre participantes com relação a uma questão considerada importante naquele contexto. No LV, eventualmente alguma freqüentadora surpreende a amabilidade cotidiana manifestando abertamente discordância sobre alguma fala ou posicionamento ali apresentado. Na maioria dos casos, tais controvérsias lidam com algum aspecto relativo à feminilidade/maternidade no conteúdo tratado, como aborto, sexo pós-parto, métodos contraceptivos etc.

Por vezes, comentários corriqueiros ou brincadeiras levadas a sério podem deflagrar situações tensas de conflito, por efeito de um mal-entendido. Nestes casos, dependendo de quem são os/as envolvidos/as, pode ser necessário um delicado trabalho interacional de reconciliação das partes.

No início das atividades na rede, comportamentos disruptivos eram relativamente raros, uma vez que os/as participantes pertenciam ao mesmo grupo, acadêmicos/as e técnicos/as em computação. Com a popularização das atividades online, surgiram diferentes formas de ataque à ordem estabelecida em ambientes de Internet. $\mathrm{O}$ anonimato e ausência de riscos característicos da $\mathrm{CMC}$ permitem, a participantes mal-intencionados/as, ações disruptivas das mais diversas ordens, usando comportamentos deliberadamente agressivos para tumultuar e desestabilizar grupos formados nesses espaços. ${ }^{10}$ Assim, um/a único/a agressor/a é capaz de provocar danos consideráveis à relação de confiança e cordialidade entre um grupo.

A falta de censura e controle estatal sobre as informações geradas e distribuídas através da Internet contrasta enormemente com a situação dos meios de comunicação de massa tradicionais, sujeitos à regulação e controle formalizados de

\footnotetext{
10 Para uma aprofundada discussão sobre comportamentos disruptivos no ciberespaço, ver Sternberg (2001).
} 
seus conteúdos. Através da legislação e do aprimoramento dos programas, os provedores de acesso à Internet têm tentado exaustivamente fornecer ambientes com privacidade e segurança na rede para seus/suas usuários/as exercerem suas atividades. Entretanto, o compartilhamento de informação nesse espaço sofre poucas restrições, e qualquer tipo de ponto de vista pode ser livremente expressado. Em situações de conflito, cabe aos/às próprios/as participantes conter os excessos a partir de recursos puramente interacionais.

\section{Teorização informal da feminilidade}

A considerar o processo dinâmico de atualização da cultura de gênero, no contexto interacional do weblog, é interessante notar o uso particular que as freqüentadoras fazem das categorizações ligadas à feminilidade, à maternidade e ao papel de gênero feminino em suas vidas cotidianas. Assim como Garfinkel via nas ações dos membros comuns da sociedade a aplicação de princípios sociológicos em estado prático, da mesma forma, pode-se pensar as posições assumidas pelas freqüentadoras, em seus discursos e práticas, como teorizações informais, métodos cotidianos que implicam um repensar da situação feminina e da tensão entre permanência e mudança nos atributos de gênero.

É importante ressaltar que este "repensar" não é apresentado como uma reflexão organizada que visaria, por exemplo, uma ação transformadora para a situação social feminina, mas como métodos práticos de enfrentamento de situações concretas vividas no cotidiano, como "etnométodos" (Garfinkel, 1984).

As negociações de sentido acerca da femininilidade e da maternidade propostas neste espaço interacional constituem o que tenho chamado de um repensar o feminino. De todos os aspectos estudados nesta pesquisa, este elemento parece orientar todo o conteúdo temático presente nas trocas comunicativas do grupo, perpassando cada uma das estruturas obtidas no processo de análise, constituindo-se provavelmente no mecanismo discursivo mais característico desta interação, um padrão interacional.

Esta postura por parte das participantes, entretanto, não parece ter a intenção de nenhuma ação transformadora da sociedade em um nível mais amplo. Nos limites do circuito estabelecido em torno do weblog, e mesmo nos espaços 
ocupados pelas blogueiras nas mídias tradicionais - quando das várias entrevistas em jornais, revistas e televisão a que compareceram pela grande projeção alcançada durante esses anos de atividade -, a posição de repensar as práticas femininas ocorre apenas em um âmbito pessoal e individual, como etnométodos. O termo etnométodo refere-se às "propriedades racionais das expressões indiciais e outras ações práticas como realizações contingentes e contínuas das práticas engenhosamente organizadas da vida cotidiana (Garfinkel, 1984, p. 11)." ${ }^{11}$ Em outras palavras, etnométodos são saberes aplicados contingencialmente, em situações concretas, situadas caso a caso. Sendo assim, é possível observar uma desvinculação voluntária das participantes de qualquer posição política que vise a um encaminhamento coletivo das questões ali refletidas.

Esta disposição para repensar, para teorizar informalmente a feminilidade na sociedade contemporânea surge como um meio de enfrentar situações concretas vividas pelas participantes no cotidiano. Interessadas em toda informação a respeito da realidade que vivem como mães, essas mulheres posicionam-se frente aos saberes tradicionais, aos saberes especializados e alternativos, às posições pessoais díspares das amigas digitais, a elaborar uma teorização informal da feminilidade que orienta suas ações no cotidiano para todos os fins práticos, mas não políticos. "Sociólogas em estado prático," (Garfinkel, 1984) discutem, experimentam e teorizam a feminilidade como questão privada.

\section{Conclusões}

A observação da dinâmica interacional da entrada em cena de novas participantes revela aspectos da lógica simbólica que organiza este espaço, em um processo de apresentação do self - como na formulação goffmaniana - que regula e organiza a interação ali ocorrente. Os protocolos de interação desenvolvidos nos ambientes de Internet parecem ter no elogio um componente fundamental. Apesar de existirem weblogs contemplando as temáticas mais variadas, o elogio parece ser a mediação principal nos processos de reconhecimento, acolhimento e pertencimento nesses ambientes. Na criação do circuito comunicativo que se gera em torno de cada

\footnotetext{
${ }^{11}$ Tradução pessoal. No original: “... rational properties of indexical expressions and other practical actions as contingent ongoing accomplishments of organized artful practicies of everyday life."
} 
ambiente, aspectos característicos de outros contextos sociais podem ser observados. Os/as leitores/as de um weblog, por exemplo, não constituem uma categoria homogênea. Participantes são recebidos/as de acordo com o capital simbólico que possuem - adquirido através de processos próprios de legitimação -, que na medida em que esteja garantido, os/as participantes podem mesmo prescindir da mediação do elogio em suas trocas para terem boa acolhida.

Uma forma de interação social marcante nos ambientes on-line consiste no conflito. Uma vez aplicados os protocolos tácitos de relacionamento neste ambiente, grupos de afinidade se formam através da interação escrita, tendo como padrão preponderante uma sociabilidade amena. Entretanto, eventualmente os conteúdos veiculados suscitam uma ruptura neste padrão interacional, gerando situações de conflito, que podem variar de um rápido mal-entendido a divergências conceituais de grande duração. Os conflitos surgidos evidenciam pontos de tensão entre os saberes e posições em jogo, eventualmente desnudando contradições e diferenças irredutíveis entre participantes. Nessas situações, o grupo tende a centralizar-se em torno de posições intolerantes, a criar uma unidade que visa a definir uma posição grupal no enfrentamento da situação. Após o desfecho, retorna-se à existência independente de cada uma das participantes, tendo definido, porém, limites mais precisos e posições coletivamente aceitas, que passarão a reger a interação naquele ambiente, fortalecendo-se assim uma cultura própria do grupo, com repertórios tácitos para futuras contendas.

A emergência de um papel social feminino renovado é um processo complexo que encontra entraves históricos, e que se refletem ao longo das interações com o grupo pesquisado, tanto nos comentários do LV quanto nas entrevistas com as participantes. Muitas são as contradições e ambigüidades, principalmente no que tange à relação com os valores tradicionais ligados à feminilidade. Parece haver neste sentido uma aplicação de princípios sociológicos em estado prático, métodos cotidianos de enfrentar situações concretas que incluem um questionamento da situação feminina contemporânea e suas tensões com as matrizes tradicionais acerca dos atributos de gênero. As negociações de sentidos nesse domínio apresentam uma convergência de posições próxima de um consenso sobre a coexistência de um feminismo responsável por benefícios e direitos conquistados pelas mulheres desta 
geração e de um persistente machismo que desaceleraria estes processos. Em um exercício freqüente de duvidar dos arranjos estabelecidos, essas mães refletem sua própria situação, e assim, parecem conscientes da reprodução de papéis de gênero inerente ao processo de educação dos/as filhos/as. Assim como repensam a feminilidade e a maternidade no âmbito de suas práticas cotidianas, se propõem a repensá-la a partir da ação de instituições formais de ensino, de produtos culturais, dos saberes especializados e tradicionais. Pratica-se assim uma teorização informal da feminilidade, que busca repensar práticas e costumes sociais. Esta prática, entretanto, não apresenta envolvimento com uma ação organizada, refletida e comprometida com ações de transformação política.

\section{Referências Bibliográficas}

BRITTOS, Valério C. “Televisão e barreira: as dimensões estética e regulamentar.” In: Othon Jambeiro; César Bolaño; Valério Brittos (Orgs.). Comunicação, informação e cultura: dinâmicas globais e estruturas de poder. Salvador: EDUFBA, 2004, v. 1, p. 15-42.

COYNE, Richard. Technoromanticism: Digital narrative, Holism and the Romance of the Real. Cambridge, Mass.: MIT, 1999.

GARFINKEL, Harold. Studies in Ethnomethodology. Cambridge, Polity Press/Oxford, Blackwell Publishing Ltd., 1984.

GIDDENS, Anthony. Modernidade e Identidade. Rio de Janeiro: Jorge Zahar Ed., 2002.

GOFFMAN, Erving. A Representação do Eu na Vida Cotidiana Petrópolis: Vozes, 1998.

HORROCKS, Christopher. Marshall McLuhan and Vituality. Cambridge, Icon Books, 2001.

LOGAN, Robert. "The Five Ages of Communication". In: Explorations in Media Ecology (1/1) pp. 13-20. New Jersey: Hampton Press, 2002.

ONG, Walter. "Ecology and Some of its Future". In: Explorations in Media Ecology (1/1) pp. 5-11. New Jersey: Hampton Press, 2002.

. "Oralism to Online Thinking”. In: Explorations in Media Ecology (2/1) pp. 43-45. New Jersey: Hampton Press, 2003.

POSTMAN, Neil. Tecnopólio: a rendição da cultura à tecnologia. São Paulo, Nobel, 1994.

SIMMEL, Georg. Sociologia. São Paulo, Ática, 1983. 
SMITH, Greg. “Instantâneos 'sub specie aeternitatis:' Simmel, Goffman e a sociologia formal.” In: GASTALDO, Édison (org.) Erving Goffman, desbravador do cotidiano. Porto Alegre, Tomo Editorial, 2004.

STERNBERG, Janet. Misbehavior in Cyber places: the regulation of online conduct in virtual communities on the Internet. PhD Thesis on Culture and Communication. School of Education, New York University, 2001. 